\title{
A Smart growth evaluation system based on Analytic Hierarchy Process
}

\author{
Yannan Sun ${ }^{\text {a) }}$,Shanshan Qiao ${ }^{\text {b) }}$, Yang Yang ${ }^{\text {c) }}$ \\ School of North China Electric Power University, Baoding, 071000, China \\ a)1414966613@qq.com,b)1327957449@qq.com,c)1270076779@qq.com
}

Keywords: Smart growth, Evaluation system, Analytic Hierarchy, Process

\begin{abstract}
With the acceleration of urbanization, urban planning becomes more and more important. We did some in-depth discussion about sustainable city and smart growth initiatives in this paper.

Firstly, we define a metric which is a comprehensive index to measure the success of smart growth of a city. On the basis of a comprehensive analysis of the all factors that affect the smart growth of urban, we use the Analytic Hierarchy Process (AHP), which is a combination of quantitative and qualitative methods to define the metric. We select the smart growth index as the target layer, the three E's of sustainability (Economically prosperous, socially Equitable, and Environmentally Sustainable) as the principle layer. Besides, we select seven indicators (e.g. Gini coefficient, Employment growth rate) from a series of factors by using Cluster analysis and Principal component analysis to constitute the solution layer. Hence, we get a three-layer evaluation system.

Secondly, we select Pittsburgh as our evaluation object. Using the metric defined and the data collected, we get the evaluation results of success of smart growth. Pittsburgh's current development plan does well in meeting the smart growth principle.

Thirdly, according to the problems reflected in the evaluation results, combined with the local specific situation, we make the plans of sustainable development for the it-strengthening infrastructure construction of public transportation preferentially and constructing some distinctive places for residence.

The suggestions and measures based on the evaluation results will be helpful for the sustainable development of cities.
\end{abstract}

\section{Introduction}

At the end of the 1990s, Americans were aware of the problems of suburbanization, such as excessive energy consumption, the decrease of Agricultural land and open space, the dispersion of jobs and so on. Hence, smart growth came into being. ${ }^{[1]}$ It is projected that by 2050, 66 percent of the world's population will be urban - this will result in a projected 2.5 billion people being added to the urban population. ${ }^{\text {[2] }}$ The application of smart growth is much important than ever."Smart growth" covers a range of development and conservation strategies that help protect our health and natural environment and make our communities more attractive, economically stronger, and more socially diverse. ${ }^{[3]}$

\section{The Smart Growth Index}

For the first task, we use the Analytic Hierarchy Process (AHP) to define a metric to measure the success of smart growth of a city. We decide to use the above three $\mathrm{E}$ as the elements of the criterion layer.

We propose a simplified two-step method to simplify the evaluation system.

Step1. We chose a series of indicators. Then we use the method of cluster analysis to classify these indicators.

Step2. Principal component analysis was used to select the main factors for the classified data.

After the above two-step simplification, we screen the following seven indicators as the elements of scheme layer. 
- The changing rate of GDP

-Employment growth rate

- Gini coefficient

- The changing rate of rent as a percentage of household income

- Population growth rate

- Proportion of agricultural land

- Proportion of public transport travel

We visualize the evaluation system in Figure 1.

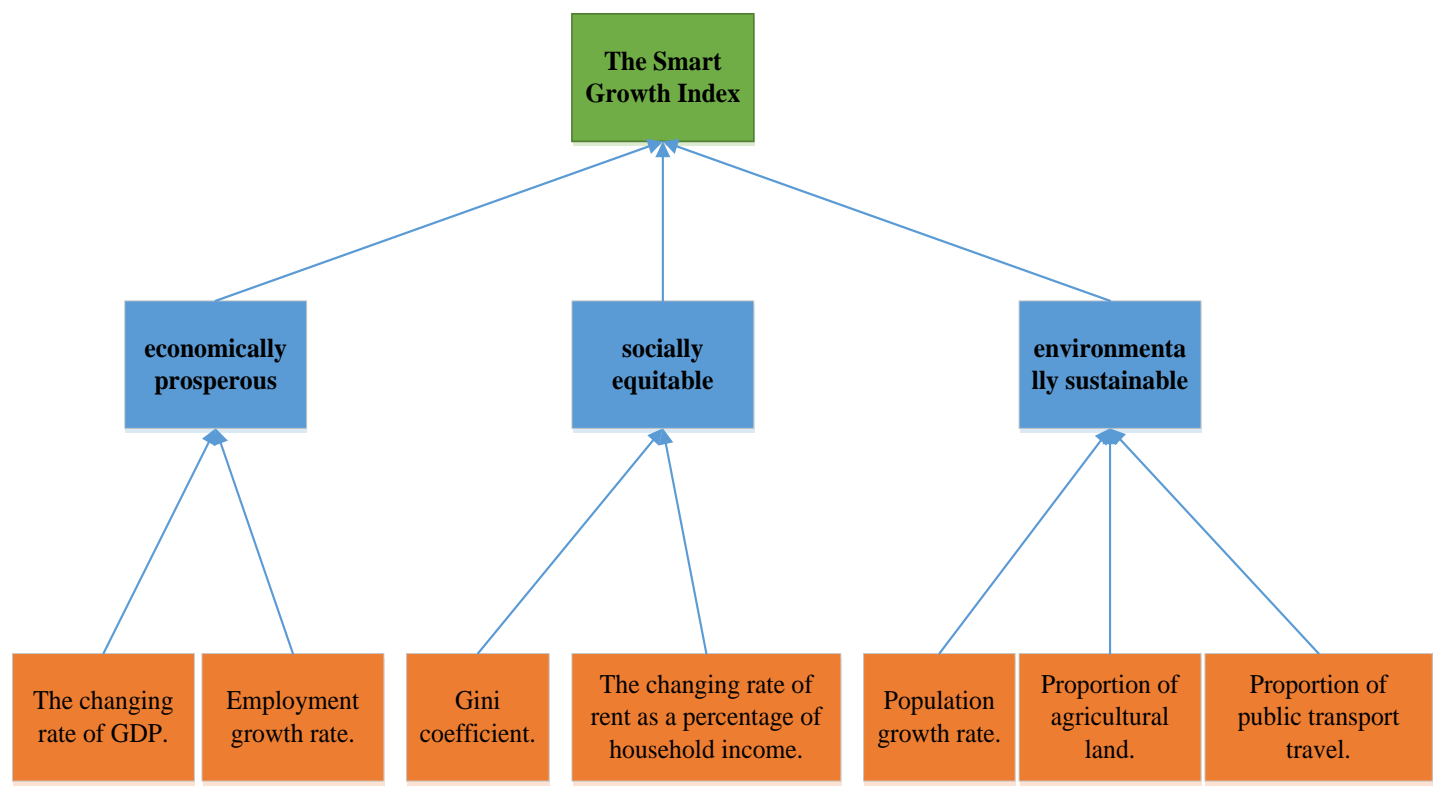

Figure 1. The evaluation system using AHP

The overview of evaluation process1.Using AHP to get the weight of each indication of the lowest layer.

2.We give the criteria for the classification of these indexes and the corresponding scores are also given.

3.We multiply the score of each index by its weight and then add up all the values obtained. Hence, we can get the final score of this evaluated target.

4.Consistency check. ${ }^{[4]}$

\section{Measure the current development plan}

We choose Pittsburgh as our evaluation target. We get the data of the seven indicators mentioned in the Smart Growth Index from U.S. Census Bureau, U.S. Department of Agriculture. The Smart Growth Index of Pittsburgh is 7. We can draw a conclusion that Pittsburgh does well in the aspects of economy and transportation with lacking in terms of land use and income distribution. Proportion of agricultural land is relatively less, indicating that degree of urban sprawl is stronger.

Make smart growth plan

With the results we get in measuring the current development plan of the Pittsburgh, we also consider the local situation and the principle of smart growth to make plan for it. The development and adjustment of urban functions constitute the driving force for the development of the city, and the city's policy, natural environment, accessibility, etc. constitute the external driving force for the development trend of the city. Therefore, according to the geographical environment and policies of the Pittsburgh, we define the development plan of the city by analyzing and defining the growth boundary of the Pittsburgh. ${ }^{[5]}$

The plan for Pittsburgh. The urban area of Pittsburgh is 144 square kilometers and population is 330000 . We can calculate the limit population of the region according to the level of ecological space supply. According to the city ecological land and reasonable level of per capita ecological space, we analyze the suitability of Pittsburgh City population scale. According to the principle of smart growth, we get the equivalent forest area in the future is about $45 \%$ of the area, and the per 
capita equivalent forest area of 180 square meters. Hence, we get that Pittsburgh's urban population limit is 360000.The present situation of Pittsburgh: its population is decrease year by year with more and more people move to the suburbs. Pittsburgh's traffic is very convenient, highway, railway and water transport developed. In economics, biotechnology, computer technology, robotics, health care, finance is an important pillar. Therefore, the future development needs of the government to take measures to guide the transfer of population to the city, to prevent the spread of the city. So we think that the government should

1) Strengthen infrastructure construction of public transport priority. Pittsburgh traffic is very convenient, so we should give full play to the advantages of this area for the convenience of the public travel. At the same time, the government should introduce policies to encourage the public to make full use of public transport and reduce the rate of private cars.

2) Construct some distinctive places for residence. One of the important reasons for the low living rate of the city is that the dwelling place is in the pursuit of luxury, lacking the attraction of the individual character and the real human spirit. Therefore, the government should build a distinctive feature of the community, while providing a certain size of housing security for low-income families and migrant workers to provide affordable housing.

Based on the above plan, we have improved the Gini coefficient and the population growth rate in the local measures, and then used AHP analysis to verify the correctness of our plan.

\section{Conclusion}

We use the Analytic Hierarchy Process (AHP) to define a metric to measure the success of smart growth of a city. Then we apply the metric to measure the current development plan of Pittsburgh. Pittsburgh's current development plan does well in meeting the smart growth principle, which agrees with the fact. we can draw a conclusion that Pittsburgh does well in the aspects of economy and transportation with lacking in terms of land use and income distribution. Proportion of agricultural land is relatively less, indicating that degree of urban sprawl is stronger.

\section{Strengths}

- AHP can deals with the problem of combining qualitative and quantitative. The subjective judgment and policy experience can be introduced into the model and quantified.

-We use a simplified two-step method when select indicators.

There are many options available, if we take too many indicators into consideration, the condition will be extremely complex and is not in favor of analysis.

\section{Weakness}

\section{-The limitation of data available}

Due to the limitation of the data can be collected, our results and conclusions have a certain deviation compared with the fact. We can get more fair evaluations and detailed plans with the more exhaustive data.

\section{-The limitation of AHP}

We can only choose the best in a given policy. In the AHP method, it is necessary to compare the consistency of the AHP method, and if it does not meet the requirements of the consistency index, the method will lose its function.

\section{References}

[1] Xianglong Tang, A survey of smart growth,Vol.8(Nov,2009),(pp98-102) Urban problems.

[2] https://esa.un.org/unpd/wup/Publications/Files/WUP2014-Highlights.pdf

[3]http://www.epa.gov/smartgrowth.

[4]http://www.Sustainablecitiesinstitude.org/Documents/SCI/Report_Guide/Guide_EPA_SmartGro wthGHGReduction_2011.pdf_ 
[5]Qiyuan Jiang, Mathematical Model,, pp 249-262, Beijing: Higher Education Press, 978-7-04-031150-1 